\title{
Metastatic Urothelial Carcinoma
}

National Cancer Institute

\section{Source}

National Cancer Institute. Metastatic Urothelial Carcinoma. NCI Thesaurus. Code C126109.

An urothelial carcinoma which has spread from the original site of growth to another anatomic site. 